\title{
Ambientalização curricular: estudo de caso do curso de tecnologia em logística
}

\author{
Curricular environmental: case study of the logistics technology course
}

\author{
Mario Sergio Cunha Alencastro* \\ Jorge Wilson Michalowski*
}

\section{Resumo}

Em consonância com os princípios da transversalidade e da interdisciplinaridade, procurou-se verificar, no currículo do curso, uma abordagem metodológica que contemplasse, mediante metodologias ativas e participativas, um processo de ensino e aprendizagem que tratasse as questões ambientais de forma transversal e integrada. Nesse contexto, este estudo procurou analisar como se insere a ambientalização curricular. A pesquisa desenvolvida, um estudo de caso que utilizou como instrumentos a pesquisa bibliográfica, a análise documental, a observação participante e o grupo focal, demonstrou que a prática ambiental pode ser trabalhada de maneira transversal e interdisciplinar, aliada com o mercado atual, em busca de soluções para problemas reais. Este estudo de caso proporcionou uma evolução significativa na construção do conhecimento dos alunos, futuros profissionais de logística, os quais demonstraram mais interesse nos conteúdos quando colocados à frente de problemas reais de empresas, tendo que indicar soluções para um mercado competitivo do qual em breve serão parte ativa.

Palavras-chave: Ambientalização curricular. Educação ambiental. Tecnologia educacional.

\section{Abstract}

In line with the principles of transversality and interdisciplinarity, the course curriculum was designed as a methodological approach that contemplated, through active and participatory methodologies, a teaching and learning process that addressed environmental issues in a transversal and integrated way. In this context the present study sought to analyze how the curricular ambientization is inserted. The research developed, a case study, used as instruments the documentary analysis, participant observation and focus group. The research developed shows that the environmental practice can be worked in a transversal and interdisciplinary way allied with the current market, through the practice in the search for solutions to real problems. This case study provided a significant evolution in the knowledge construction of the students, future logistics professionals, who showed more interest in the contents, when faced with real problems of companies, having to present solutions for a competitive market in which they will soon be active.

Keywords: Curricular Ambientalization. Environmental education. Educational technology.

Recebido em 27/09/2018 - Aprovado em 31/01/2019

http://dx.doi.org/10.5335/rep.v26i2.8686

\footnotetext{
Doutor em Meio Ambiente e Desenvolvimento pela Universidade Federal do Paraná. Professor Pesquisador no Mestrado em Educação e Novas Tecnologias do Centro Universitário Internacional, Brasil. E-mail: siderly.a@uninter.com

** Mestre em Educação e Novas Tecnologias pelo Centro Universitário Internacional. Professor da FAE Centro Universitário, consultor em planejamento e logística, sócio-diretor da Magnificat Consultoria em Planejamento e Logística, Brasil. E-mail: jotawil@terra.com.br
} 


\section{Introdução}

Esta pesquisa inicia-se com o estudo da ambientalização curricular vinculada aos princípios da transversalidade e da interdisciplinaridade, o qual procurou verificar, no currículo do curso de Tecnologia em Logística, uma abordagem metodológica que contemplasse, mediante metodologias ativas e participativas, um processo de ensino e aprendizagem que tratasse as questões ambientais de forma transversal e integrada.

A inserção de conhecimentos, valores sociais e éticos e questões ambientais nos estudos e currículos universitários é de suma importância para o desenvolvimento de um profissional educado para a sustentabilidade socioambiental, no sentido de torná-lo comprometido com a sociedade, para que esta tenha mais qualidade de vida, permitindo que as gerações futuras usufruam de um meio ambiente propício à vida.

Relatam Speller, Robl e Meneghel (2012) que vários países do mundo debatem sobre a alteração em seus sistemas de ensino e indagam sobre a contribuição das instituições de ensino superior (IESs) na construção do conhecimento diante dos desafios da globalização e da responsabilidade social, possibilitando o desenvolvimento de uma sociedade mais justa, que tenha consciência dos valores éticos, para garantir melhor qualidade de vida.

Leff (2002), por sua vez, afirma que a crise ambiental é um problema do tempo atual e que gera discussão e reflexão a respeito do conhecimento ambiental, pois está voltada à construção de uma sociedade justa e sustentável. A inserção ambiental não deve limitar-se às disciplinas na matriz curricular, mas envolver ações práticas estruturadas, em que o processo ambiental possa ocorrer dentro do funcionamento da IES. Diante do exposto, este estudo analisa a inserção da educação ambiental no currículo do curso de Tecnologia em Logística, por meio de uma reforma acadêmica que alinhou o ensino do citado curso ao mercado.

A escolha por esse curso originou-se da necessidade de realizar uma reforma acadêmica nele. Considerando do atual Projeto Pedagógico do Curso (PPC), percebeu-se que não havia em seu arcabouço a ambientalização curricular. Da mesma forma, a interdisciplinaridade não estava adequada, não permitindo que a prática da realidade das questões da vida fosse vivenciada. Para isso, foi necessário analisar a legislação pertinente quanto à educação ambiental, os instrumentos de avaliação de curso do Ministério da Educação no tocante ao contexto educacional na introdução no currículo do processo de ensino-aprendizagem, o PPC e o Plane- 
jamento de Desenvolvimento Institucional (PDI), sustentado pelos estudos sobre ambientalização curricular de renomados autores.

O objetivo geral foi, por meio da reforma acadêmica, desenvolver a ambientalização curricular, inserindo a dimensão socioambiental, em que é tratada de forma inadequada. De forma secundária, foi estudada a legislação e procurou-se investigar outras instituições que oferecem o mesmo curso, com a expectativa de entender se aplicam a ambientalização curricular.

A IES em que foi realizada a pesquisa trata-se de um centro universitário particular, sediado na cidade de Curitiba. Com a análise do PDI e do PPC, verificou-se que a preocupação da universidade é trabalhar na prática a temática ambiental, mediante oficinas, embora tenha no currículo conteúdos em disciplinas específicas, como logística reversa e internacional e o estudo do homem contemporâneo. Analisaram-se três semestres, com três oficinas e três feiras de logística, em que os alunos apresentaram soluções sustentáveis para problemas elaborados por eles mesmos e de empresas do mercado, que contribuíram durante esse período indicando problemas reais a serem solucionados pelos acadêmicos.

\section{Ambientalização curricular}

Para adentrar na ambientalização curricular, torna-se necessário entender os conceitos que a norteiam. Relembrando Leff (2002), a crise ambiental é um problema do tempo atual, que conduz à discussão e à reflexão sobre temas ambientais. Nesse contexto, as IESs tornam-se muito importantes na inserção da temática ambiental, haja vista ser um problema de conhecimento para o qual é imprescindível repensar as práticas humanas e seus efeitos sobre o meio ambiente com relação à preservação da vida de todas as espécies (GUERRA; FIGUEIREDO, 2014).

Segundo Guerra e Figueiredo (2014), a ambientalização curricular inclui inserir conhecimentos, critérios e valores sociais, éticos e ambientais nos currículos universitários, visando a educar para a sustentabilidade socioambiental. Complementarmente, Kitzmann (2007 apud GUERRA; FIGUEIREDO, 2014) indica que, ao avaliar esse processo, discutem-se também os conceitos de ambientalização e de educação ambiental formal e não formal, buscando identificar a integração da dimensão ambiental em todos os níveis educativos.

De acordo com Kitzmann e Asmus (2012 apud GUERRA; FIGUEIREDO, 2014), tal conceito se define como um processo de inovação por meio de intervenções que objetivam integrar temas socioambientais aos conteúdos e às práticas das 
instituições de ensino. Assim, a ambientalização da IES tem um sentido mais amplo, ao compreender o currículo, a pesquisa, a extensão e a gestão ambiental, sendo um processo contínuo e dinâmico, para que se torne um autêntico espaço educador sustentável (GUERRA; FIGUEIREDO, 2014). Diante disso, a inserção da educação ambiental no ensino superior deve iniciar na construção do PPC, pois somente assim ela se tornará efetiva e integrada, como determina a legislação pertinente. Entende-se também que a ambientalização é capaz de tratar da transversalidade nos aspectos formativos extracurriculares, com a participação de todos os indivíduos.

$\mathrm{Na}$ esteira da definição de ambientalização curricular, Alencastro e Souza Lima (2015, p. 21) desenvolvem uma reflexão epistemológica a respeito do conceito de educação ambiental, parte daquela conceituação anterior, quando afirmam que:

[...] atualmente a questão ambiental faz-se presente nas abordagens sobre currículo, formação de professores, pesquisa e ensino em todos os níveis, e já existe um consenso sobre a importância da educação ambiental e sua inclusão curricular - como disciplina ou tema transversal - na elaboração de diversos programas educacionais.

É nesse contexto que a abordagem da ambientalização curricular deve ser entendida e aplicada no âmbito educacional, com vistas a gerar os espaços necessários às reflexões a respeito da educação ambiental, permitindo que os professores entendam e apliquem metodologias e tecnologias para atender às demandas das temáticas ambientais atuais, com a premissa de perpetuar um futuro vindouro com mais sustentabilidade e justiça social.

\section{Legislação ambiental no curso superior}

Ao abordar a ambientalização curricular, faz-se necessário analisar a legislação brasileira sobre educação ambiental, para elencar seus principais pontos norteadores na educação.

A educação ambiental foi oficializada pelo Decreto $\mathrm{n}^{\mathrm{0}}$ 73.030, de 30 de outubro de 1973, cuja letra i do art. 4 prevê: "Promover, intensamente, através de programas em escala nacional, o esclarecimento e a educação do povo brasileiro para o uso adequado dos recursos naturais, tendo em vista a conservação do meio ambiente" (BRASIL, 1973, não paginado). Já a Lei oㅜ 6.938, de 31 de agosto de 1981, em seu art. $2^{\circ}$, inciso $\mathrm{X}$, é muito enfática no sentido de ter como princípio a "[...] educação ambiental a todos os níveis do ensino, inclusive a educação da comunidade, objetivando capacitá-la para participação ativa na defesa do meio ambiente" (BRASIL, 1981, não paginado). 
A Constituição federal de 1988 aborda as questões ambientais em capítulo próprio e apresenta as bases da educação ambiental em seu art. 225 , § 1º, inciso VI, em que cita:

Art. 225. Todos têm direito ao meio ambiente ecologicamente equilibrado, bem de uso comum do povo e essencial à sadia qualidade de vida, impondo-se ao Poder Público e à coletividade o dever de defendê-lo e preservá-lo para as presentes e futuras gerações.

$\S 1$ o Para assegurar a efetividade desse direito, incumbe ao poder público:

[...]

VI - promover a educação ambiental em todos os níveis de ensino e a conscientização pública para a preservação do meio ambiente (BRASIL, 1988, não paginado).

Ainda, o Decreto no 99.274 , de 6 de junho de 1990, que regulamenta a Lei $\mathrm{n}^{\mathrm{o}}$ 6.902, de 27 de abril de 1981, e a Lei oㅜ 6.938, de 31 de agosto de 1981, estabelece, em seu art. $1^{\circ}$, inciso VII: “[...] orientar a educação, em todos os níveis, para a ativa participação do cidadão e da comunidade na defesa do meio ambiente, cuidando para que os currículos escolares das diversas matérias obrigatórias contemplem 0 estudo da ecologia" (BRASIL, 1990, não paginado).

Portanto, torna-se necessário que as instituições de ensino tomem conhecimento e apresentem ações práticas no cumprimento da legislação, a fim de alcançar os objetivos que esta propõe. Nesse sentido, o Plano Nacional de Educação (PNE), aprovado pela Lei $\mathrm{n}^{\circ}$ 13.005, de 25 de junho de 2014, com vigência entre 2014 e 2024, define metas como compromissos entre o Estado e as instituições de ensino para o avanço da educação brasileira, no intuito de consolidar e garantir que o sistema educacional promova a formação para o trabalho, com o firme exercício da cidadania, ao estabelecer, no item $\mathrm{X}$ do art. $2^{\circ}$, "promoção dos princípios do respeito aos direitos humanos, à diversidade e à sustentabilidade socioambiental" de suas diretrizes (BRASIL, 2014, não paginado).

Complementarmente, o Instrumento de Avaliação de Cursos de Graduação Presencial e a Distância (BRASIL, 2017), em seu item 1.5, sobre conteúdos curriculares, Dimensão 1 - Organização didático-pedagógica, enfatiza que a IES deve abordar conteúdos pertinentes à política de educação ambiental, previstos e implantados de maneira excelente para o desenvolvimento do perfil profissional do egresso, de forma sistêmica e global, corroborado pelo item 16 , dos requisitos legais e normativos, em que consta que a temática ambiental deve ser trabalhada de forma transversal.

Com o avanço tecnológico do século XXI, o Brasil e os demais países do mundo continuam em evolução constante, com a finalidade de normatizar cada vez mais a 
questão ambiental no contexto educacional, conforme as leis descritas nesse espaço histórico.

\section{Aprendizagem baseada em problemas}

No decorrer da pesquisa, verificaram-se os conceitos de ambientalização e o conteúdo da legislação vigente relativa à educação superior e à educação ambiental, tornando-se fundamental uma mudança de comportamento, com o envolvimento e o comprometimento do indivíduo e da coletividade no sentido de construir uma sociedade pautada na responsabilidade social, não somente com a teoria, mas atuando com ações práticas, pois, de acordo com a afirmação de Freire (1996, p. 21), todo educador necessita entender e saber que "[...] ensinar não é transferir conhecimento, mas criar as possibilidades para a sua produção ou a sua construção".

Entre as possibilidades de abordagem metodológica que contemple o uso de metodologias ativas e participativas nos processos de ensino e aprendizagem, destaca-se a aprendizagem baseada em problemas (ABP). Trata-se de um modelo didático que proporciona ensino-aprendizagem integrado e contextualizado e cuja inspiração deu-se por meio da teoria de John Dewey (PEREIRA et al., 2007). Com a utilização da pedagogia ativa ou da ação de Dewey, a proposta é que a aprendizagem se origine a partir de problemas ou circunstâncias situacionais que deixam a desejar, gerando desconforto ou dúvidas, possibilitando usar experiências reais que motivem os alunos a práticas de investigação, para encontrar uma solução criativa, inovadora e eficaz para os problemas.

Souza e Dourado (2015) identificam quatro vantagens da ABP: (i) a motivação, pelo dinamismo dos estudantes para aprender; (ii) a interação do conhecimento, uma vez que o estudante realiza ações práticas, o que possibilita a fixação eficaz do conhecimento adquirido; (iii) a habilidade do pensamento crítico dos conhecimentos, proporcionando condições para analisá-los criticamente para encontrar a solução dos problemas; (iv) a interação das habilidades interpessoais, fundamentais para o trabalho em equipe. Quanto aos métodos, estes se baseiam na teoria construtivista de Jean Piaget e no método de investigação-ação de Paulo Freire, colocando-se como uma alternativa pedagógica em relação aos demais métodos de ensino existentes. 


\section{Percurso metodológico da pesquisa}

Nesta pesquisa, optou-se pela estratégia de estudo de caso, tendo em vista que se pretende aprofundar uma unidade individual. Segundo Collis e Hussey (2005), o estudo de caso é o exame extensivo de um único exemplo de interesse, considerando-se uma abordagem fenomenológica. Por sua vez, Yin (2015, p. 17) enfatiza que: "[...] o estudo de caso é uma investigação empírica que investiga um fenômeno contemporâneo (o 'caso') em profundidade e em seu contexto de mundo real, e especialmente quando os limites entre o fenômeno e o contexto não puderem ser claramente evidentes".

O caso escolhido foi o do curso de Tecnologia em Logística de uma IES particular da cidade de Curitiba, no qual se iniciou um processo de ambientalização curricular. Para sua consecução, foram utilizados como recursos a pesquisa bibliográfica, a análise documental, a observação participante e o grupo focal.

$\mathrm{Na}$ etapa do grupo focal, convidaram-se 16 representantes de empresas dos setores de indústria, varejo e serviços, dos quais somente 10 estiveram presentes, com a finalidade de realizar uma reunião para apresentação da nova matriz curricular. A escolha desse recurso deveu-se por se tratar de um método de coleta de dados que, de acordo com Vergara (2010), tem por objetivo a discussão de um tópico específico para possibilitar a coleta de informações por meio das interações grupais, diante de um debate aberto em torno de um tema de interesse comum aos participantes.

Foi apresentado aos participantes que o objetivo do grupo focal era visualizar a nova matriz curricular, elaborada dentro de aspectos técnicos, e perceber como a interdisciplinaridade, a transversalidade e a ambientalização se faziam presentes, a fim de contribuir no processo de sua melhoria, com suas percepções, atitudes e práticas de mercado, de modo a atender adequadamente às exigências do próprio mercado.

Por sua vez, a observação participante possibilitou aos pesquisadores fazer parte da equipe que desenvolveu o estudo de caso, tendo contato direto e frequente com os envolvidos no processo da reforma acadêmica, pelo período de um ano e meio, em que foram ativos, configurando-se, portanto, uma observação participante completa.

A IES sobre a qual este estudo debruçou-se localiza-se na cidade de Curitiba, no estado do Paraná, sendo o terceiro estado com curso de Tecnologia em Logística, o que demonstra a importância deste, bem como a aceitação pelo mercado de traba- 
lho. A escolha do curso em questão e dos participantes da pesquisa deveu-se ao fato de ele ter recebido a designação de um novo coordenador, assim como à necessidade de realização de uma reforma acadêmica, exigência do regulamento interno da universidade quando transcorrido quatro anos da última. É importante ressaltar que o PPC prevê a formação de profissionais em Logística, contemplando o desenvolvimento de competências e habilidades na correta gestão dos impactos ambientais, apresentando soluções eficientes e eficazes, com postura ética e responsável.

Os trabalhos envolveram outros coordenadores de cursos de tecnologia, os quais estavam na mesma situação de reforma curricular de seus cursos, a saber, Gestão Comercial e Gestão Financeira. Sendo todos cursos de tecnologia, entendeu-se que seria importante que os três cursos elaborassem a reforma acadêmica de maneira conjunta na parte comum, com as particularidades tratadas pelo seu respectivo coordenador, diante da legislação e das diretrizes pertinentes. Construiu-se um cronograma de trabalho, em que as reuniões aconteceriam na IES, com a direção de campus, os coordenadores e a equipe de suporte da Diretoria Acadêmica, que estavam empenhados em proporcionar todo o apoio necessário para que a reforma tivesse cunho inovador e sustentável.

A matriz curricular, segundo o coordenador do curso, foi organizada por competências, de modo a possibilitar a aplicação do conhecimento adquirido durante $o$ semestre numa prática de solução de um problema real de uma empresa ou de sua própria necessidade profissional (Quadro 1). 
Quadro 1 - Características da ambientalização da matriz curricular do curso de Tecnologia em Logística

\begin{tabular}{|c|c|}
\hline \multicolumn{2}{|r|}{ Matriz Curricular - Características de um estudo ambientalizado } \\
\hline Característica & Descrição \\
\hline 1 - Complexidade & $\begin{array}{l}\text { As oficinas de gestão, de projeto de armazéns, de gestão de distribuição e de } \\
\text { gestão de logística lean contextualizam. }\end{array}$ \\
\hline $\begin{array}{l}2 \text { - Ordem disciplinar: } \\
\text { flexibilidade e permeabi- } \\
\text { lidade }\end{array}$ & $\begin{array}{l}\text { A matriz contempla a participação de diferentes profissionais das áreas do conhe- } \\
\text { cimento. Utiliza temáticas atuais relativas à logística. Há disciplinas obrigatórias e } \\
\text { optativas I e II. }\end{array}$ \\
\hline 3 - Contextualização & $\begin{array}{l}\text { As oficinas de gestão incorporam problemas reais locais e globais, possibilitando } \\
\text { incorporar as dimensões ambiental, social e econômica, com parcerias em em- } \\
\text { presas. Essa situação é concluída com a Feira de Logística e a apresentação das } \\
\text { soluções pelas equipes. }\end{array}$ \\
\hline $\begin{array}{l}4 \text { - Considerar o sujeito da } \\
\text { aprendizagem na constru- } \\
\text { ção do conhecimento }\end{array}$ & $\begin{array}{l}\text { As disciplinas têm adequação metodológica com a participação de alunos e pro- } \\
\text { fessores de forma equilibrada. }\end{array}$ \\
\hline $\begin{array}{l}5 \text { - Considerar aspectos } \\
\text { cognitivos, afetivos e de } \\
\text { ação das pessoas }\end{array}$ & $\begin{array}{l}\text { A instituição, por meio do curso, fornece apoios psicológico, pedagógico e econô- } \\
\text { mico aos alunos, como a saúde escolar, o sistema de bolsas e financiamentos e os } \\
\text { cursos de extensão, com vistas a melhorar a performance dos alunos nos estudos. }\end{array}$ \\
\hline $\begin{array}{l}6 \text { - Coerência e reconstru- } \\
\text { ção entre teoria e prática }\end{array}$ & $\begin{array}{l}\text { Os alunos, em todas as disciplinas, realizam trabalhos práticos e coerentes com } \\
\text { a teoria, com identificação de atitudes individuais e coletivas no desenvolvimento } \\
\text { dos projetos. Já houve projetos que se tornaram empresas reais. }\end{array}$ \\
\hline $\begin{array}{l}7 \text { - Orientação prospecti- } \\
\text { va de cenários alterna- } \\
\text { tivos }\end{array}$ & $\begin{array}{l}\text { Em todos os conteúdos ministrados, há a preocupação da formação do profissio- } \\
\text { nal comprometido com o futuro e a sociedade, bem como se busca a utilização de } \\
\text { tecnologias atuais com visão do futuro, como Google Classroom, Mobile, Google } \\
\text { Drive, etc. }\end{array}$ \\
\hline $\begin{array}{l}8 \text { - Adequação metodo- } \\
\text { lógica }\end{array}$ & $\begin{array}{l}\text { Presença de estudos de campo. Utilização da metodologia de resolução de pro- } \\
\text { blemas e metodologias participativas e ativas, tais como (ABP) e entre pares ou } \\
\text { times. }\end{array}$ \\
\hline $\begin{array}{l}9 \text { - Oferecer espaços de } \\
\text { reflexão e participação } \\
\text { democrática }\end{array}$ & $\begin{array}{l}\text { Práticas de trabalhos participativos e colaborativos estão previstas em todas as } \\
\text { disciplinas, com participação de alunos e professores. }\end{array}$ \\
\hline $\begin{array}{l}10 \text { - Compromisso para a } \\
\text { transformação das rela- } \\
\text { ções sociedade-natureza }\end{array}$ & Característica que será abordada no decorrer do curso. \\
\hline
\end{tabular}

Fonte: elaboração dos autores, 2018.

Essa matriz, embora atendesse aos requisitos legais e aos da instituição em estudo, ainda não havia sido validada pelo mercado de trabalho, ou seja, pelas empresas que no futuro utilizarão os serviços profissionais dos estudantes que irão colar grau e receber o diploma de Tecnólogo em Logística e terão atuação real nessas organizações, que anseiam por resultados auspiciosos para torná-las mais competi- 
tivas e eficientes em seu segmento de mercado. Para tanto, o coordenador convidou empresários dos segmentos indústria, comércio e serviços para um encontro, em 13 de setembro de 2016, com a finalidade de fazer uma investigação qualitativa, do tipo grupo focal, sobre os anseios e as necessidades das empresas que representavam, validando a matriz curricular elaborada e fazendo ajustes e adequações necessários para considerar as demandas atuais do mercado e de sustentabilidade.

O encontro contou com a presença de dez empresas, por meio de seus representantes, entre eles, diretores, gerentes, funcionários e ex-alunos do curso, totalizando 13 pessoas. Apresentada a metodologia empregada na reforma acadêmica e na matriz curricular, passou-se a palavra para que os presentes apresentassem suas percepções e o que poderia ser melhorado. Individualmente, cada um posicionou-se com relação às partes técnica e metodológica, aprovando a reforma acadêmica. Ao término da exposição individual, foi solicitado ao grupo que apresentasse o que mais deveria ser abordado para que essa reforma atendesse plenamente aos anseios do mercado. $\mathrm{O}$ grande grupo, após discussão dos assuntos inerentes à formação do futuro profissional, relacionou os seguintes aspectos:

a) abranger conteúdo técnico que atenda às necessidades das empresas;

b) capacitar os alunos em leitura/escrita e em postura ética;

c) formar profissionais com visão sistêmica, adaptados a cumprir metas, enfrentar desafios, saber dividir e trabalhar com espírito de colaboração, comprometidos com o trabalho;

d) contemplar a inserção de conhecimentos socioambientais no currículo, para que o profissional seja educado para a sustentabilidade socioambiental, haja vista que o cenário atual exige sustentabilidade das empresas para serem competitivas;

e) desenvolver nos futuros profissionais o compromisso como pessoa;

f) ensinar a receber um não, assimilando isso como desenvolvimento pessoal, e trabalhar com o comportamento do indivíduo;

g) apresentar como o mercado se encontra e o cenário em que atuarão;

h) desenvolver nos alunos a negociação - entre colegas e entre setores, tanto internos quanto externos;

i) trazer os problemas das empresas e de ex-alunos para dentro da sala, para estudar soluções e apresentar ao mercado; 
j) convidar os empresários para fazer seus depoimentos e dar palestras sobre assuntos das organizações, no cenário do curso;

k) ensinar aos alunos a prática da paciência e a não serem imediatistas.

Depois da reunião com o grupo focal, em consonância com os princípios da transversalidade e da interdisciplinaridade, procurou-se introduzir no currículo do curso uma abordagem metodológica que contemplasse um processo de ensino e aprendizagem que tratasse os pontos abordados na matriz curricular, os apontamentos do grupo focal e as questões ambientais de forma transversal e integrada. Nesse sentido, criou-se um espaço que recebeu o nome de Oficina de Gestão, regrado por regulamento próprio da instituição, com aprovação da Pró-Reitoria de Ensino, Pesquisa e Extensão, permitindo que os alunos desenvolvessem a capacidade de aplicação de conceitos e teorias estudados durante o curso de forma integrada, proporcionando-lhes a oportunidade de confrontar as teorias estudadas em cada semestre com as práticas profissionais existentes, encontrando soluções para problemas reais, valendo-se de critérios e valores sociais, éticos, estéticos e ambientais. As empresas participantes do grupo focal se dispuseram a apresentar problemas reais de logística em seu segmento de mercado para que os alunos pudessem analisar, assim como abrir para visitas, para que conhecessem in loco a problemática e realizassem o estudo, resultando em propostas para tais situações, nas disciplinas denominadas Oficinas de Gestão.

Com esse espaço, portanto, busca-se estimular no aluno a análise e explicação do objeto de seu estudo, culminando em novas propostas de soluções, na forma de produto, projeto técnico, estudo de caso, proposta de intervenção em procedimentos em serviços, adequação tecnológica ou processos e técnicas que tenham responsabilidade socioambiental. No fim de cada semestre, é realizada uma Feira de Logística, com a finalidade de entregar ao mercado as soluções alcançadas diante dos problemas apresentados aos alunos no decorrer do semestre letivo.

As equipes são formadas pelos próprios alunos e o problema a ser solucionado surge dela própria ou envolve temas a serem solucionados para problemas fornecidos pelas empresas parceiras da instituição. Na Feira de Logística, os estudantes apresentam, explicam, justificam e demonstram, por meio de maquetes ou novos processos, para o público externo e alunos dos demais cursos de graduação da IES, a solução encontrada. Dessa maneira, verificou-se que os pontos importantes da nova matriz curricular referem-se ao engajamento dos alunos durante o semestre, à pesquisa de campo e às visitas técnicas às empresas para entender o problema e encontrar uma solução. $\mathrm{O}$ trabalho em equipe possibilita a eles negociar entre si 
e com outras equipes, melhorar o relacionamento interpessoal, ter mais responsabilidades e cumprir os prazos, vivenciando a realidade do profissional de logística, sempre considerando a temática ambiental.

A primeira feira contou com 21 alunos, distribuídos em 6 equipes, das quais são apresentadas 5, a seguir:

a) APL Logistics: abordou uma solução de otimização de armazenagem, com elaboração de uma maquete concretizando a solução teórica - equipe com três alunos.

b) Criapneu: trouxe solução em logística reversa para utilização de pneus usados de maneira alternativa e criativa, com a produção de bancos, camas para cães e gatos, entre outros - equipe com três alunos.

c) Projeto Recolorir: desenvolveu uma solução em logística reversa para reaproveitamento de giz de cera, apresentando um processo de derretimento de tocos de giz usados e produção de novos em outros formatos, com a mesma qualidade - equipe com cinco alunos.

d) Tijolinho do Bem: desenvolveu uma solução em logística reversa para utilização de lixo orgânico na produção de tijolos, expondo um projeto de usina que beneficia o lixo orgânico, tendo como resultado uma pasta como matéria-prima para produção de tijolos - equipe com três alunos.

e) Zoo Nacional: apresentou solução em armazenagem e distribuição de alimentos para zoológicos, na expectativa de otimizar a estocagem de produtos perecíveis e a rápida distribuição ao consumo final, evitando desperdícios e custos - equipe com dois alunos.

Observa-se que, em todas as soluções, os alunos demonstraram interesse em abordar questões ambientais, tanto para empresas quanto para a sociedade.

Finalizada a reforma acadêmica em 2016, a nova matriz curricular passou a vigorar no início de 2017, período contemplado por este estudo de caso, que buscou responder como trabalhar a temática ambiental de forma transversal no curso superior de Tecnologia em Logística.

\section{Considerações finais}

Durante a pesquisa, notou-se que, devido ao avanço tecnológico, aliado à nova cultura da sociedade, o desafio da IES é entender as características do perfil do aluno ingressante no curso, como também as necessidades que as organizações de- 
mandam na atualidade, em um cenário globalizado, marcado pela competitividade e, principalmente, pela sustentabilidade.

Nas oficinas realizadas, que culminaram nas Feiras de Logística, as temáticas ambientais abordadas foram relativas à logística reversa, incluindo a reutilização do vidro, a recuperação do óleo de fritura de uma empresa e a otimização de armazéns de forma a não agredir o meio ambiente, no caso da equipe que apresentou solução para reduzir os desperdícios de manuseio da soja entre o produtor e a armazenagem.

Verificou-se, no piloto de implantação em uma turma com a antiga matriz, que alunos e professores tiveram que se aproximar mais, interagindo e trabalhando colaborativamente, oportunizando pensar, refletir e tomar decisões diante de situações anteriormente realizadas somente pelo docente. Essa condição gerou uma nova cultura de comportamento, passando mais responsabilidade aos alunos. Com a primeira Oficina de Gestão e a Feira de Logística, pôde-se aprender mais sobre os comportamentos, o trabalho de pessoas com opiniões diferentes, que precisaram se unir em torno de um único objetivo, exercitando a negociação, a parceria, a paciência e a confiança. As empresas parceiras avaliaram muito bem as soluções apresentadas, dispondo-se a continuar com esse vínculo, fornecendo problemas reais da organização para que os alunos possam encontrar soluções eficientes e sustentáveis.

A realização do grupo focal com os empresários para validação da proposta da reforma do curso e a implantação dessa nova metodologia na reforma acadêmica foram fundamentais para o êxito das oficinas de gestão, uma vez que eles contribuíram muito para a construção do conhecimento e a formação do novo profissional de logística. Ainda, as oficinas de gestão possibilitaram aos professores um empenho mais firme e seguro na efetiva aprendizagem dos estudantes, fazendo-os rever conceitos e buscar mais conhecimento para subsidiar os alunos na elaboração de soluções dos problemas expostos. Dessa maneira, a interdisciplinaridade e a transversalidade se tornaram presentes, como resultado de uma visão ampla, que rompeu a fragmentação das disciplinas, oferecidas de modo isolado. Com um olhar abrangente da realidade, tanto dos alunos quanto do mercado, e eixos centrais unificadores da nova matriz curricular, reintegrou-se o processo acadêmico, oportunizando a transversalidade dos assuntos e temas ambientais, tão importantes e urgentes no cenário atual.

Este estudo de caso proporcionou, na observação destes pesquisadores, uma evolução significativa na construção do conhecimento dos alunos, futuros profis- 
sionais de logística, os quais demonstraram mais interesse nos conteúdos, quando colocados à frente de problemas reais de empresas, tendo que indicar soluções para um mercado competitivo do qual em breve serão parte ativa.

Ao concluir, é mister que, em estudos futuros, aprofunde-se a importância dessa metodologia, mas com outras formas de realizar a mesma temática, para que essa aprendizagem tenha uma ação continuada, integrando mais alunos, professores, empresas e a própria instituição, preocupados com a temática ambiental, de modo que a formação dos futuros profissionais se proceda de maneira interdisciplinar e transversal, contribuindo para uma sociedade mais ética, justa e sustentável.

\section{Referências}

ALENCASTRO, Mario Sergio; SOUZA LIMA, José Edmilson de. Educação ambiental: breves considerações epistemológicas. Revista Meio Ambiente e Sustentabilidade, Curitiba, v. 8, n. 4, p. 20-50, jan./jun. 2015. Disponível em: <http://www.grupouninter.com.br/revista meioambiente/ index.php/meioAmbiente/article/view/42>. Acesso em: 23 fev. 2017.

BRASIL. Decreto n. 73.030, de 30 de outubro de 1973. Cria, no âmbito do Ministério do Interior, a Secretaria Especial do Meio Ambiente - SEMA, e dá outras providências. Diário Oficial da União, Brasília, DF, 30 out. 1973. Disponível em: <http:/www2.camara.leg.br/legin/fed/decret/1970-1979/ decreto-73030-30-outubro-1973-421650-publicacaooriginal-1-pe.html>. Acesso em: 27 nov. 2017.

. Lei n. 6.938, de 31 de agosto de 1981. Dispõe sobre a Política Nacional do Meio Ambiente, seus fins e mecanismos de formulação e aplicação, e dá outras providências. Diário Oficial da União, Brasília, DF, 2 set. 1981. Disponível em: <http://www.planalto.gov.br/ccivil_03/leis/L6938. htm>. Acesso em: 13 out. 2016.

Constituição (1988). Constituição da República Federativa do Brasil de 1988. Brasília, DF: Senado Federal, 1988. Disponível em: <http://www.planalto.gov.br/ccivil_03/constituicao/ constituicaocompilado.htm>. Acesso em: 20 set. 2016.

Decreto n. 99.274, de 6 de junho de 1990. Regulamenta a Lei $\mathrm{n}^{\circ}$ 6.902, de 27 de abril de 1981, e a Lei $\mathrm{n}^{\circ} 6.938$, de 31 de agosto de 1981, que dispõem, respectivamente sobre a criação de Estações Ecológicas e Áreas de Proteção Ambiental e sobre a Política Nacional do Meio Ambiente, e dá outras providências. Diário Oficial da União, Brasília, DF, 7 jun. 1990. Disponível em: <http://www.planalto.gov.br/ccivil_03/decreto/antigos/d99274.htm>. Acesso em: 5 jun. 2017.

Lei n. 13.005, de 25 de junho de 2014. Aprova o Plano Nacional de Educação - PNE e dá outras providências. Diário Oficial da União, Brasília, DF, 26 jun. 2014. Disponível em: <http:// www.planalto.gov.br/ccivil_03/_ato2011-2014/2014/lei/113005.htm>. Acesso em: 18 fev. 2017.

. Ministério da Educação. Instituto Nacional de Estudos e Pesquisas Educacionais Anísio Teixeira. Instrumento de avaliação de cursos de graduação presencial e a distância. Brasília, DF: Inep, 2017.

COLLIS, Jill; HUSSEY, Roger. Pesquisa em administração: um guia prático para alunos de graduação e pós-graduação. Porto Alegre: Bookman, 2005. 
FREIRE, Paulo. Pedagogia da autonomia: saberes necessários à prática educativa. 25. ed. Rio de Janeiro: Paz e Terra, 1996.

GUERRA, Antonio F. Silveira; FIGUEIREDO, Mara Lúcia. Ambientalização curricular na educação superior: desafios e perspectivas. Educar em Revista, Curitiba, n. 3, p. 109-126, 2014. Disponível em: <http://www.scielo.br/pdf/er/nspe3/a08nspe3.pdf>. Acesso em: 22 maio 2017.

LEFF, Enrique. Epistemologia ambiental. São Paulo: Cortez, 2002.

PEREIRA, Clarisse F. et al. Aprendizagem Baseada em Problemas (ABP) - uma proposta inovadora para os cursos de engenharia. In: SIMPÓSIO DE ENGENHARIA DE PRODUÇÃO, 14. Anais... 2007. Disponível em: <http://www.nogueira.eti.br/profmarcio/obras/publicado_1474. pdf>. Acesso em: 8 jun. 2017.

SOUZA, Samir Cristiano; DOURADO, Luiz. Aprendizagem baseada em problemas (ABP): um método de aprendizagem inovador para o ensino educativo. Holos, Natal, ano 31, v. 5, p. 182-200, 2015. Disponível em: <http://www2.ifrn.edu.br/ojs/index.php/HOLOS/article/ view/2880/1143>. Acesso em: 8 jun. 2017.

SPELLER, Paulo; ROBL, Fabiane; MENEGHEL, Stela Maria. Desafios e perspectivas da educação superior brasileira para a próxima década. Brasília, DF: UNESCO/CNE/MEC, 2012. Disponível em: <http://unesdoc.unesco.org/images/0021/002189/218964POR.pdf>. Acesso em: 12 maio 2016.

VERGARA, Sylvia Constant. Métodos de pesquisa em administração. 4. ed. São Paulo: Atlas, 2010.

YIN, Robert K. Estudo de caso: planejamento e métodos. Tradução de Cristhian Matheus Herrera. 5. ed. Porto Alegre: Bookman, 2015. 